\title{
A SIMPLE METHOD FOR RECORDING CHANGES IN CUTANEOUS SENSIBILITY *
}

\author{
LAURENT FEINIER, M.D. \\ NEW YORK
}

The New York Neurological Institute and several other New York hospitals have adopted a method for the recording of changes in cutaneous sensibility, which on account of its simplicity is, we believe, worthy of being used as a standard. The method was suggested by Dr. Elsberg, and has served in our institution to obviate the difficulties often encountered in the understanding of the records of sensory disturbances. Whenever such a chart is examined, whether it be at the bedside or in a medical journal, it often requires considerable study before the meaning of the markings by which the different disturbances of sensibility are characterized are understood.

The sensory sheets we use at the New York Neurological Institute are of a uniform size to fit the hospital bedside chart, i. e., $8 \% 16$ inches wide by $1011 / 16$ inches long. The chart has printed on it a human figure in the anterior and posterior position (see chart). The charts are printed on paper of three colors-the white for the tactile sensation, the red for temperature and the yellow for pain. In the upper right hand corner of the sensory sheet of appropriate color is printed the sensation to be recorded. Below the body outlines is printed a key to the method of making sensory markings so that a physician who is not accustomed to making the records according to the standard can easily understand how to record the sensory disturbances.

For total loss of sensation transverse lines are made and, as transverse lines mean lost sensation, it is of little consequence how near together or how far apart the lines are drawn. It has, however, been found advantageous to make the lines $1 / 8$ to $1 / 4$ inch apart to facilitate reading. Thus, transverse lines drawn on the figures of the white sensation sheet mean anesthesia; transverse lines drawn on the figures of the red sheet (temperature) mean thermal anesthesia; transverse lines drawn on the figures of the yellow sheet (pain) mean analgesia.

Diminished sensation is represented by three varieties of oblique lines running from the right downward and to the left; for slight diminution these oblique lines are spaced $1 / 4$ inch apart; for moderate diminution $1 / 8$ inch apart, and for marked diminution $1 / 16$ inch apart. It is not to be hoped that mathematical preciseness in spacing the lines exactly according to the above measurements will always be maintained,

* From the Clinics of the Neurological Institute, New York. 
but if they are approximated a quick survey should convey an intelligent grasp of the sensory situation. Thus, oblique lines mean diminished sensation, and the nearer together the lines are the more marked is the diminution in sensation. As it is often advisable to record separately disturbances in the recognition of heat and cold, oblique lines running from right to left and downward are used to denote disturbances in the recognition of heat, and those running from left to right and downward are used to denote disturbances in the recognition of cold.

In a similar way, vertical lines show hypersensitiveness to touch, pain or temperature. The more closely together the vertical lines are, the more marked is the hypersensitiveness; thus, the vertical lines on the white sensation chart record the presence and degree of hyperesthesia; vertical lines on the yellow chart record the various degrees of hyperalgesia and those on the red chart hypersensitiveness to hot and cold.

The accompanying three charts, on which are recorded the sensory disturbances of the integument exhibited by a patient with a spinal cord tumor in the upper dorsal region, will serve as an illustration of the method used to record sensory changes.

On the white or tactile chart, it will be noted, is an anesthesia of the lower extremities extending almost to the umbilicus anteriorly and to the level of the first lumbar vertebra posteriorly. Anteriorly, above the lost sensation, there is over the upper abdomen and lower thorax an area of slight diminution in tactile sensation, and just below the left nipple an area of marked diminution. Posteriorly, sensation is lost completely to the seventh dorsal vertebra on the right with an area of moderate diminution from the level of the sixth dorsal vertebra to the first lumbar on the left.

On the yellow or pain sheet, there is an analgesia of the lower extremities with an area or band of slight hyperalgesia posteriorly at the level of the angles of the scapulae, and between this and the analgesia on the right posteriorly an area of slight hypalgesia.

Anteriorly similar changes are noted, and there is in addition a band of moderate and slight diminution in pain sense extending from the left to the right, and above this a band of moderate hyperalgesia.

Similarly, on the red or thermal sense chart there is recorded a total loss of sensation in the lower extremities, above this an area of moderate diminution, and extending around the figure above the areas of lost and diminished thermal sense, there is a band of moderately hypersensitive thermal sense.

149 East Sixty-Seventh Street. 
TACTILE

THE NEUROLOGICAL INSTITUTE, New York

Name: Mr. A.

Date: Oct. 18, 1919.

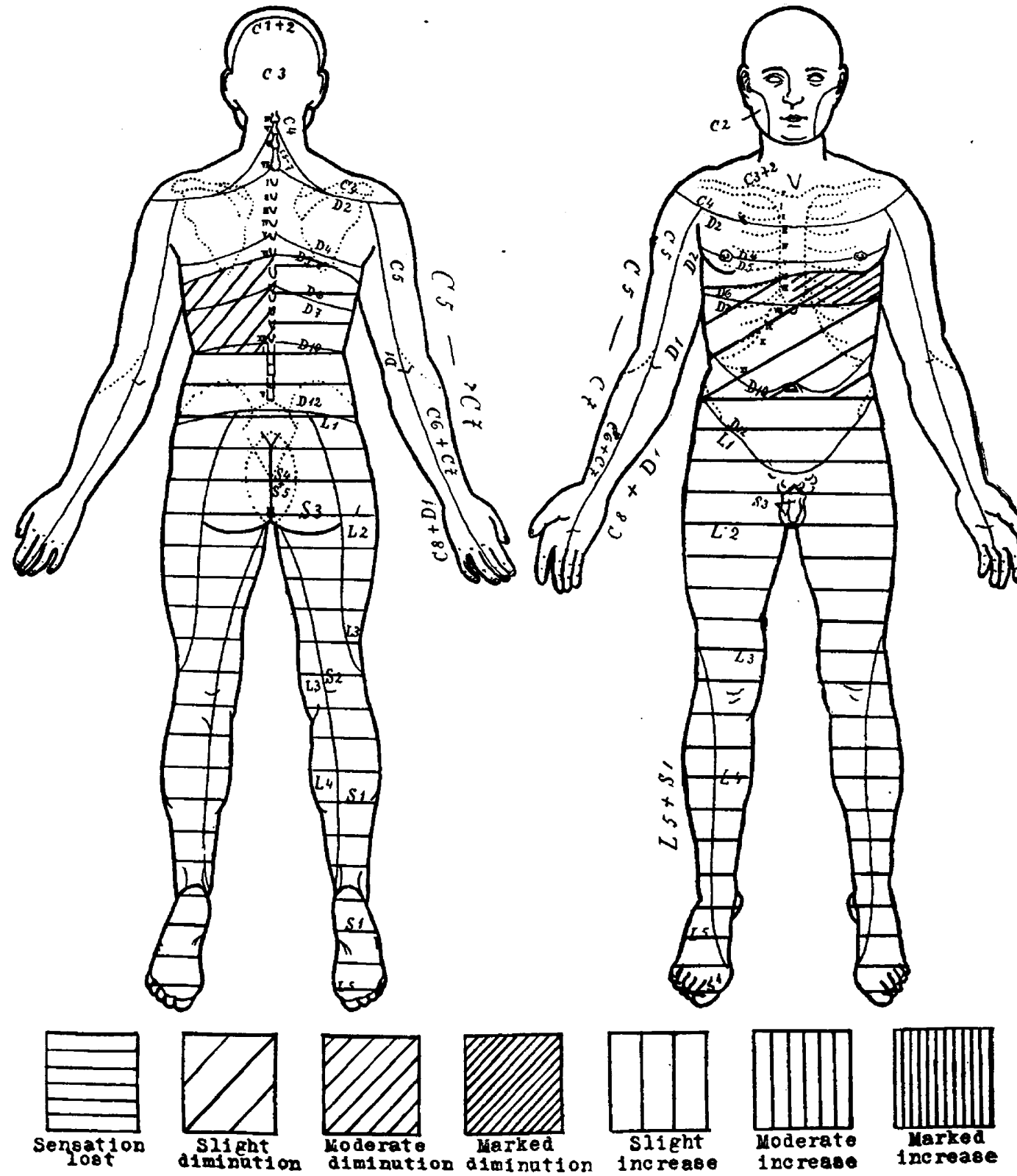


TEMPERATURE

THE NEUROLOGICAL INSTITUTE, New York

Name: Mr. A.

Date: Oct. 18, 1919.
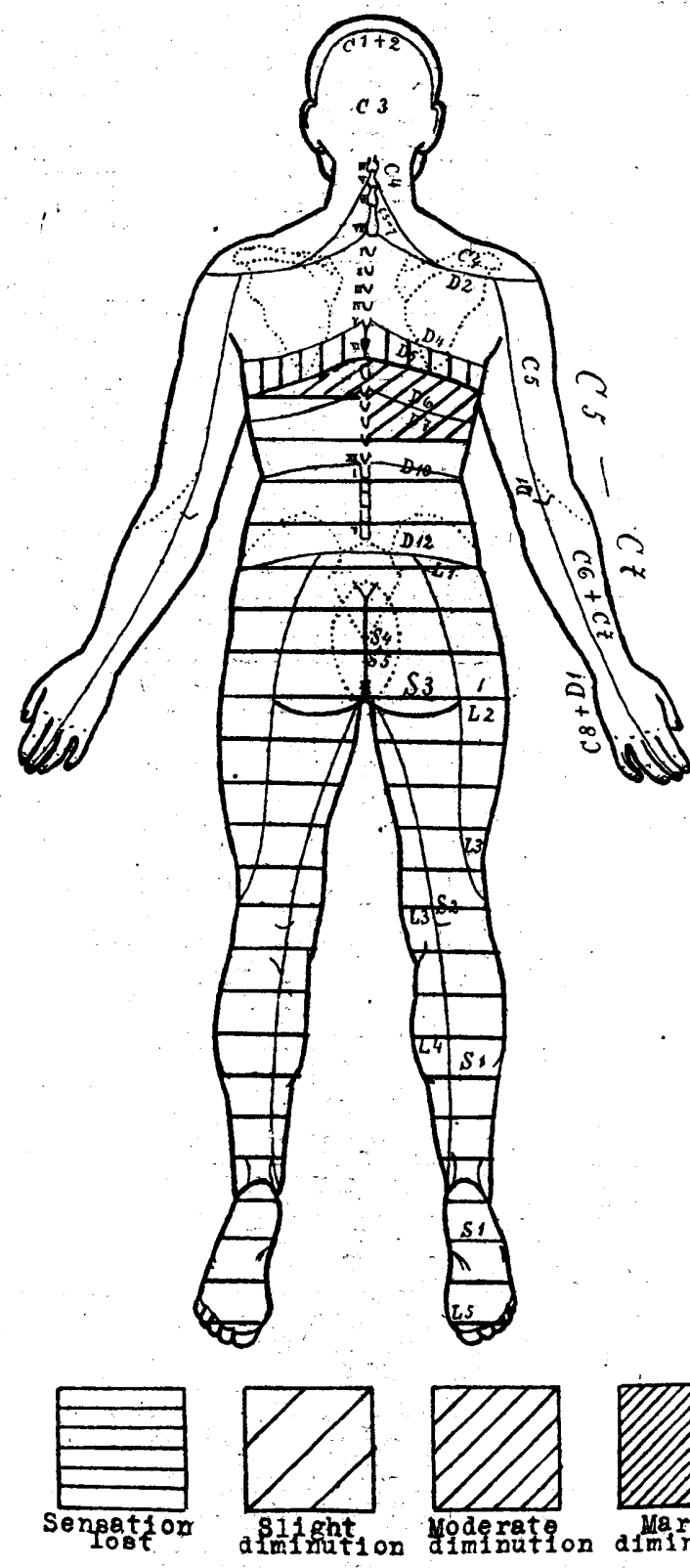

(4)
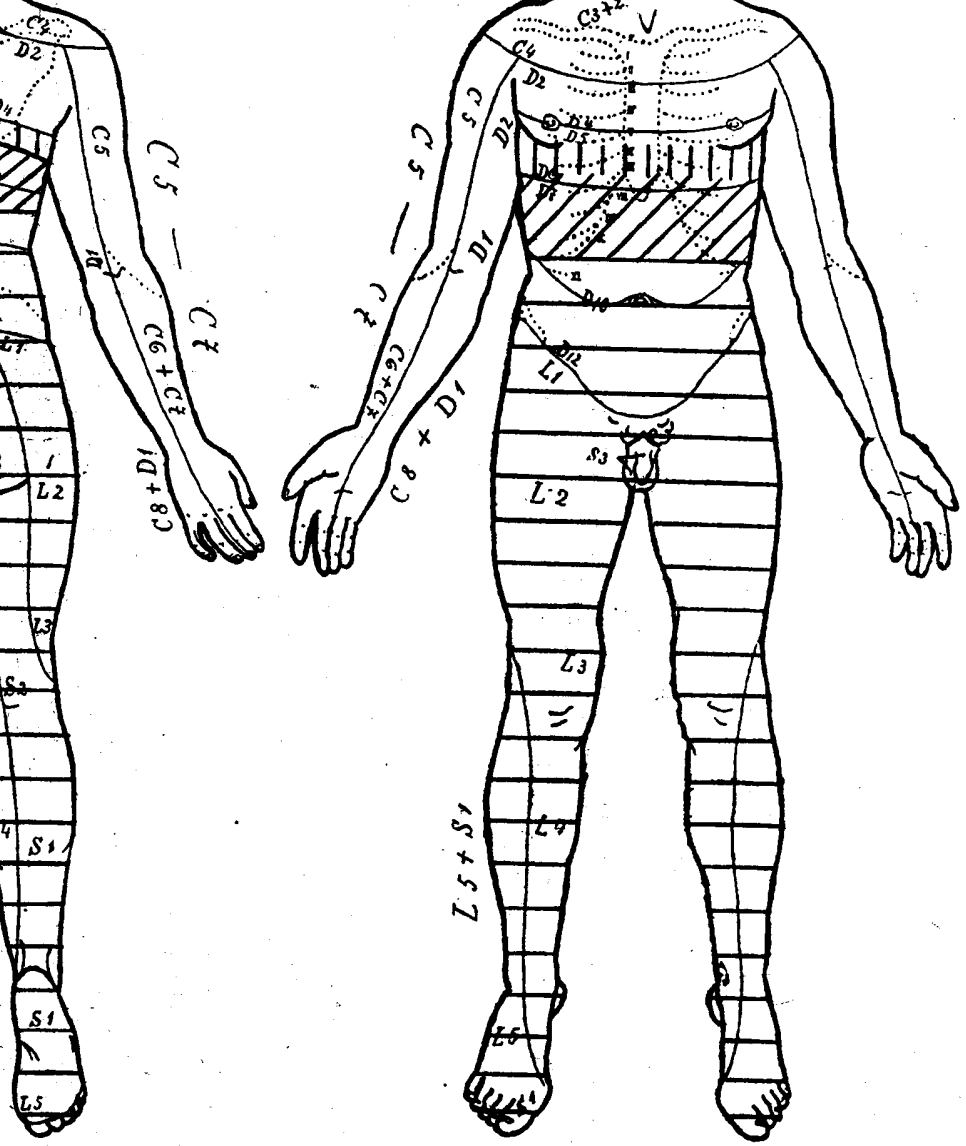


\section{PAIN}

THE NEUROLOGICAL INSTITUTE, New York

Name: Mr. A.

Date: Oct. 18, 1919.
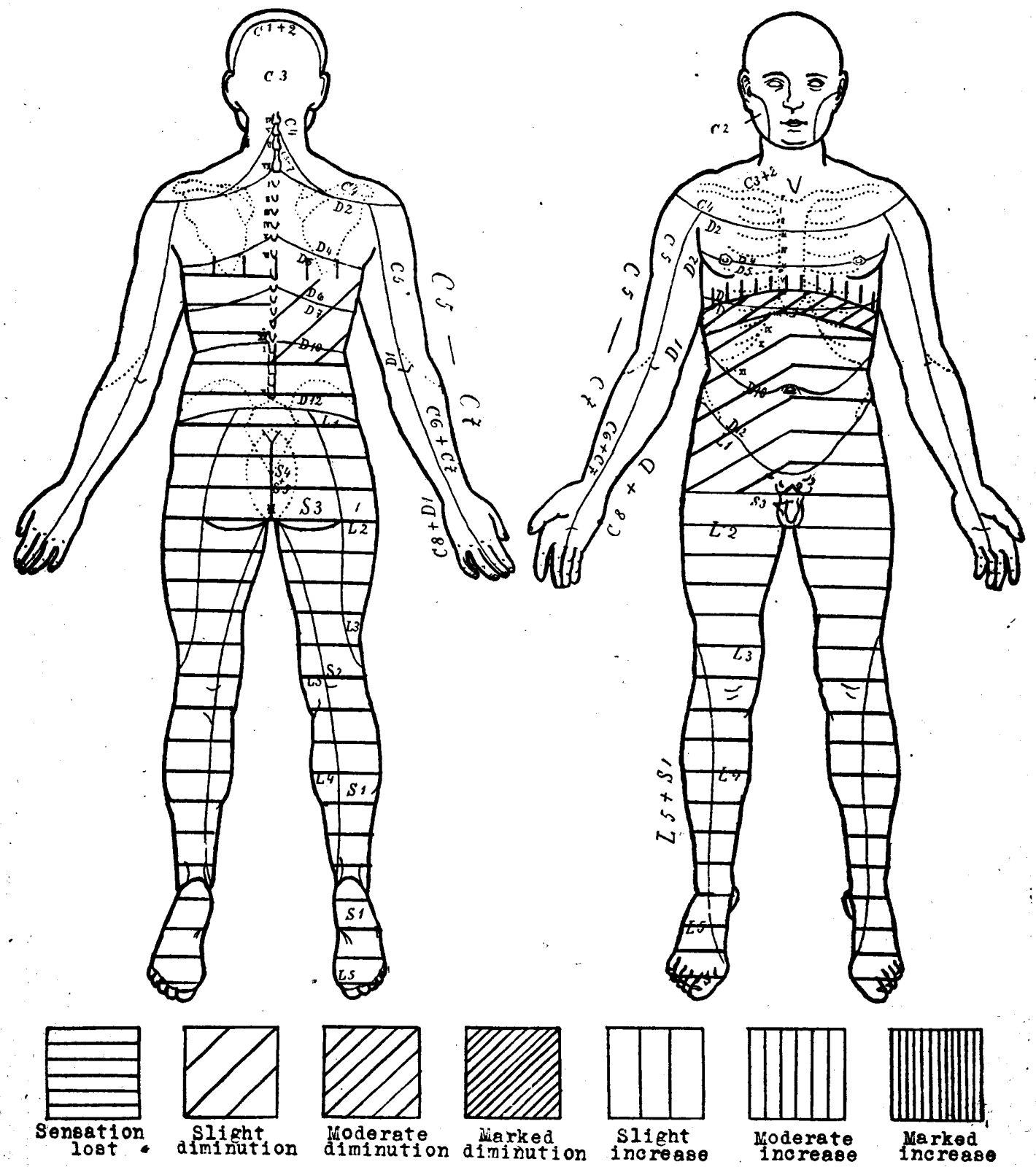